\title{
Effects of Drought on Two Small Kansas Snakes
}

\author{
Eli, John, and Ben Haines-Eitzen ${ }^{1}$, Justin and David Lee ${ }^{2}$, and George R. Pisani ${ }^{3}$ \\ ${ }^{1}$ Ithaca, New York \\ ${ }^{2}$ Pennington, New Jersey \\ ${ }^{3}$ Kansas Biological Survey, University of Kansas, Lawrence, KS 66047-3759 (gpisani@ku.edu)
}

E ffects of drought on prey-specialist snake species are seldom documented. The few pertinent studies that have been published (Seigel et al. 1995; Sperry and Weatherhead 2008; Willson et al. 2006) suggest that a lack of suitable prey leads to reduced or greatly contracted populations. Willson et al. (2006) expanded the study of Seigel et al. (1995) and showed that interspecific differences in drought response ranged from no effect (generalist species) to local extirpation (certain specialists).

The Red-bellied Snake (Storeria occipitomaculata) and the Western Smooth Earthsnake (Virginia valeriae elegans) are subjects of long-term studies by GRP (Pisani and Busby 2011; Busby et al. 2014) at the Rice Tract near Lawrence, Kansas (38.81019N, -95.17755W; WGS84). The tract (Fig. 1 ) is traversed by several transects of shelter stations using wood, tin, and carpet shelters. Both species, which are specialist predators, were severely impacted by the regional drought that affected the site from mid-2011 to September 2013.

Virginia valeriae (Fig. 2) was last captured at the site in early April 2011 and was not observed again until September

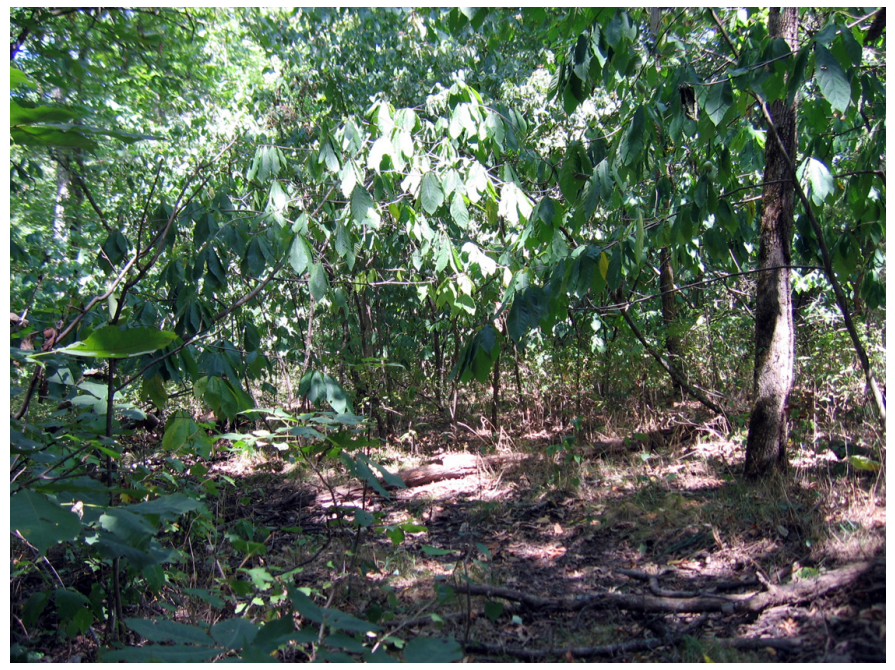

Fig. 1. Lowland habitat in the Rice Tract near Lawrence, Kansas. Photograph by George Pisani.
2013 following substantial rainfall. At that time, several adults were observed at a station occupied by a large ant (Formica subsericea) nest. The capture of several individuals immediately after precipitation resumed is suggestive of on-site survival. The nest has served as a hibernaculum for several small snake species, and $V$. valeriae might have been able to survive within the deep recesses of the nest (Pisani 2009).

Storeria occipitomaculata was last captured on 1 May 2012 (male, $278 \mathrm{~mm}$ total length, mass $4.0 \mathrm{~g}$ ); the species was not recorded from shelter transects at the tract through the duration of 2012 and subsequent years. Observations of slugs and snails (preferred prey of S. occipitomaculata at this site) similarly declined during the drought. Despite abundant moisture in the area beginning in March 2014, S. occipitomaculata was not recorded from the Rice Tract. Snail and slug populations did rebound in spring 2014, and site conditions were again favorable for the species.

On 3 August 2015, we captured a very pale-colored male S. occipitomaculata (263 mm total length, mass 4.5 g; Figs. 3 and 4) from the eastern side of the Rice Tract. Subsequent visits by GRP have yielded one additional Red-bellied Snake (female, dark-gray color morph, $281 \mathrm{~mm}$ total length, mass $7.0 \mathrm{~g}$ ). We cannot be certain, but believe it to be highly likely that the individual we captured in August emigrated from about $800 \mathrm{~m}$ west of the main study site. That area contains a small pond that retained at least some moisture and supported a population of $S$. occipitomaculata throughout the drought period (GRP, unpubl. data).

Sperry and Weatherhead (2008) estimated time to recovery of a local population of Elaphe [Pantherophis] obsoleta in Texas as "substantially more than a year" following the drought-based reduction of small-mammal prey. That estimate was based on reproduction and survival of snakes at their study site. We tentatively infer from our S. occipitomaculata capture that recovery of this species at this site will depend initially on dispersal from the refuge site followed by local reproduction. 


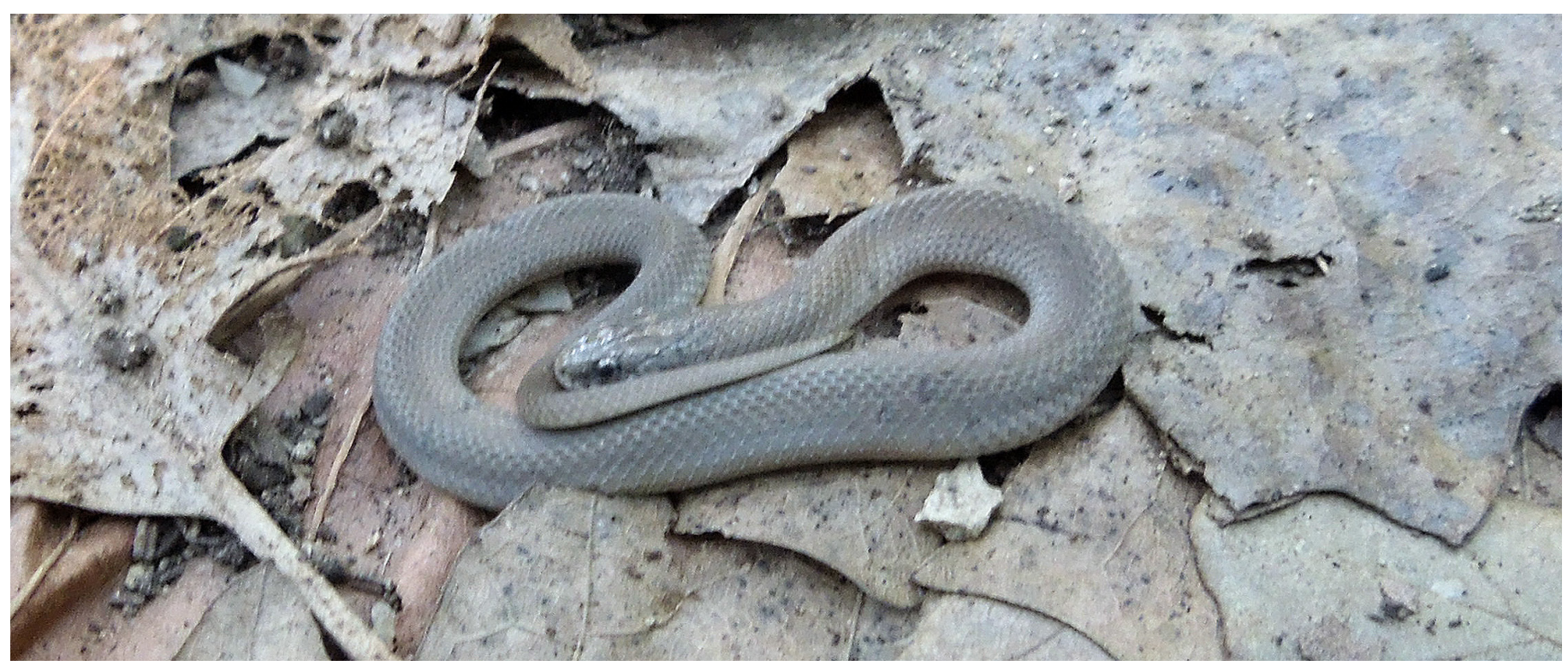

Fig. 2. A Western Smooth Earthsnake (Virginia valeriae elegans) in September 2013 at an active ant nest (ants were dormant). Photograph by Michael Zerwekh.

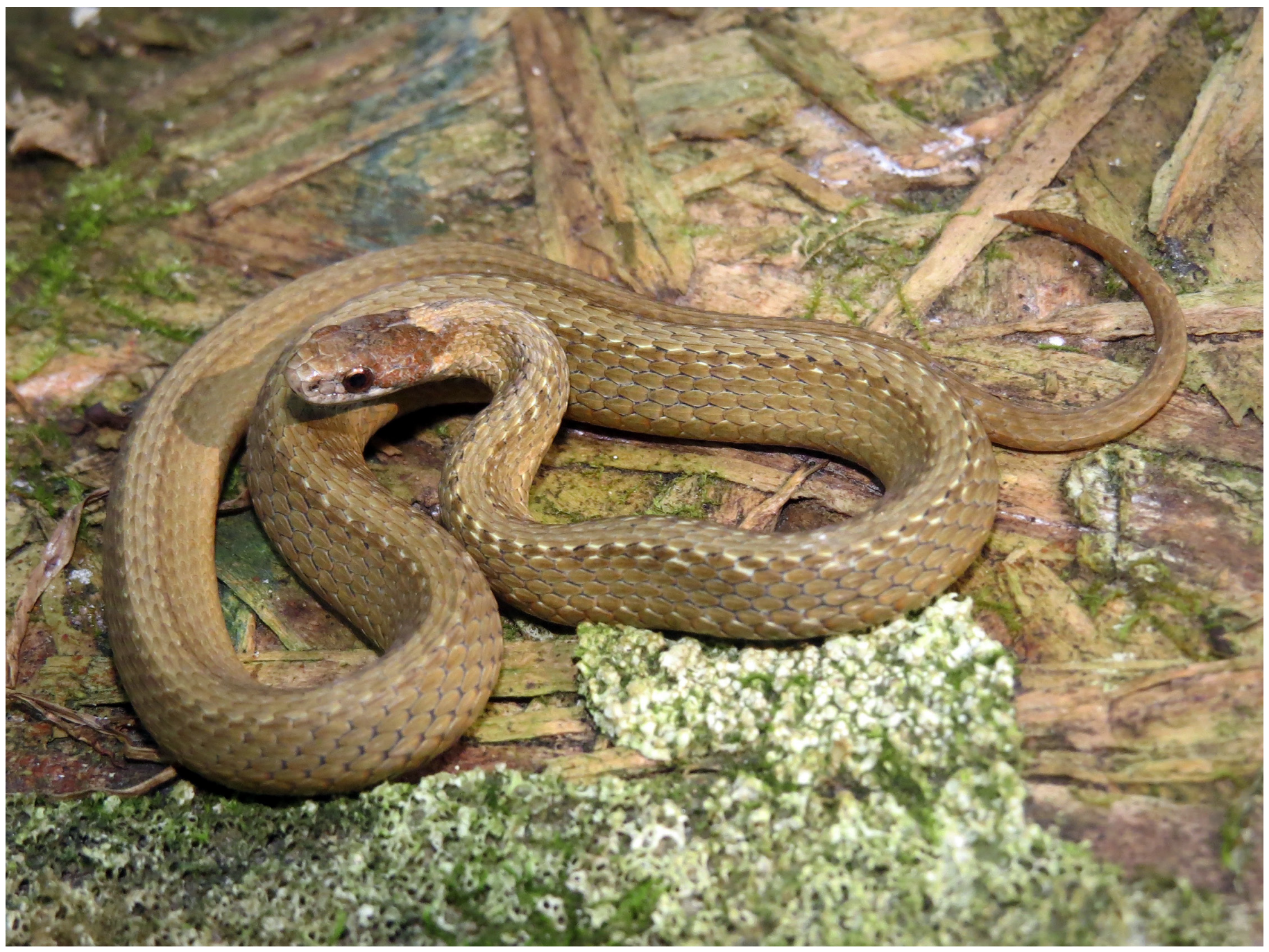

Fig. 3. A very pale-colored male Red-bellied Snake (Storieria occipitomaculata) collected in August 2015 at the Rice Tract near Lawrence, Kansas. Photograph by Justin Lee. 


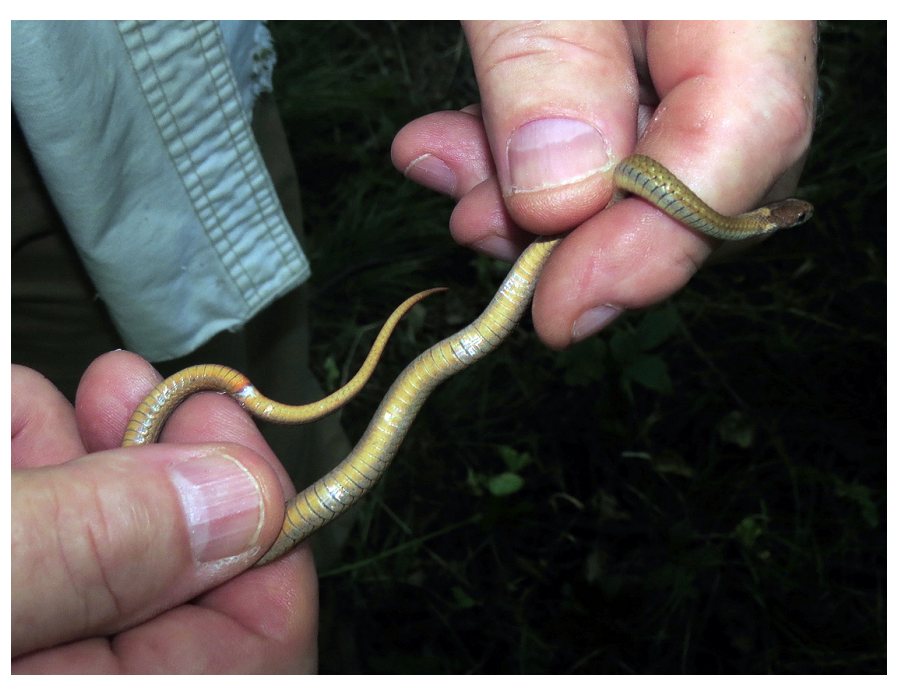

Fig. 4. Venter of the pale-colored S. occipitomaculata illustrated in Fig. 3. Photograph by Justin Lee.

\section{Literature Cited}

Busby, W.H., G.R. Pisani, E.T. Peterson, and N.Barve. 2014. Ecological studies of the Smooth Earth Snake and Redbelly Snake, and niche modeling of forest species in eastern Kansas. Open-file Report No. 179, Kansas Department of Wildlife, Parks and Tourism, Topeka.

Pisani, G.R. 2009. Use of an active ant nest as a hibernaculum by small snake species. Transactions Kansas Academy of Sciences 112:113-118.

Pisani, G.R. and W.R. Busby. 2011. Ecology of the Smooth Earth Snake (Virginia valeriae) and Redbelly Snake (Storeria occipitomaculata) in northeastern Kansas. Open-file Report No. 172, Kansas Department of Wildlife, Parks and Tourism, Topeka.

Seigel, R.A., J.W. Gibbons, and T.K. Lynch. 1995. Temporal changes in reptile populations: Effects of a severe drought on aquatic snakes. Herpetologica 51:424-434.

Sperry, J.H. and P.J. Weatherhead. 2008. Prey-mediated effects of drought on condition and survival of a terrestrial snake. Ecology 89:2770-2776.

Willson, J.D., C.T. Winne, M.E. Dorcas, and J.W. Gibbons. 2006. Post-drought responses of semi-aquatic snakes inhabiting an isolated wetland: Insights on different strategies for persistence in a dynamic habitat. Wetlands 26:10711078. 